\title{
Proteomics in Molecular Diagnosis: Typing of Amyloidosis
}

\author{
Dorothy Loo, ${ }^{1}$ Peter N. Mollee, ${ }^{2}$ Patricia Renaut, ${ }^{2}$ and Michelle M. Hill ${ }^{1}$ \\ ${ }^{1}$ The University of Queensland Diamantina Institute, The University of Queensland, Brisbane, QLD 4102, Australia \\ ${ }^{2}$ Pathology Queensland, Princess Alexandra Hospital, Woolloongabba, Brisbane, QLD 4102, Australia
}

Correspondence should be addressed to Michelle M. Hill, m.hill2@uq.edu.au

Received 28 April 2011; Revised 1 July 2011; Accepted 11 July 2011

Academic Editor: Jorge Sequeiros

Copyright () 2011 Dorothy Loo et al. This is an open access article distributed under the Creative Commons Attribution License, which permits unrestricted use, distribution, and reproduction in any medium, provided the original work is properly cited.

\begin{abstract}
Amyloidosis is a group of disorders caused by deposition of misfolded proteins as aggregates in the extracellular tissues of the body, leading to impairment of organ function. Correct identification of the causal amyloid protein is absolutely crucial for clinical management in order to avoid misdiagnosis and inappropriate, potentially harmful treatment, to assess prognosis and to offer genetic counselling if relevant. Current diagnostic methods, including antibody-based amyloid typing, have limited ability to detect the full range of amyloid forming proteins. Recent investigations into proteomic identification of amyloid protein have shown promise. This paper will review the current state of the art in proteomic analysis of amyloidosis, discuss the suitability of techniques based on the properties of amyloidosis, and further suggest potential areas of development. Establishment of mass spectrometry aided amyloid typing procedures in the pathology laboratory will allow accurate amyloidosis diagnosis in a timely manner and greatly facilitate clinical management of the disease.
\end{abstract}

\section{Introduction}

Amyloidosis is a heterogeneous group of diseases differing in cause, treatment, and prognosis. Common to this group of diseases is the mode of pathogenesis [1,2]. Amylogenic precursors misfold and assume a pathological conformation taking on a beta-pleated sheet fibrillar structure. Aggregation of these pathological proteins forms amyloid deposits in various organs eventually leading to organ failure and death. Over 20 amyloidogenic precursor proteins have been documented to form amyloid deposits systemically or localise to specific organs [3]. The amyloidogenic potential of these proteins may relate to an acquired (e.g., clonal immunoglobulin light chain in AL amyloidosis) or inherited (e.g., genetic mutations causing amino acid substitution in hereditary amyloidosis) propensity to form a structurally abnormal protein; proteins with intrinsic amyloidogenic properties which only become evident with aging (e.g., in senile systemic amyloidosis) or chronically high concentrations (e.g., serum amyloid A protein); or proteolytic cleavage of the protein precursor (e.g., $\beta$-amyloid precursor protein in Alzheimer's disease).

Treatment and prognosis depend on identifying the culprit molecule (Table 1). Because of involvement of vital organs such as the heart and kidneys, early amyloidosis identification and treatment is associated with better prognosis [4]. Treatment aimed at reducing amyloid deposits involves preventing production and aggregation of these proteins. For example, in AL amyloidosis chemotherapy or autologous haematopoietic stem cell transplantation are required to kill the clonal bone marrow plasma cells that produce the pathologic immunoglobulin light chain. Such therapies are inappropriate and in fact harmful for other types of amyloidosis. Similarly, accurate diagnosis of amyloid subtype is critical to guide organ transplantation to replace the organ that manufactures the pathogenic protein in hereditary amyloidosis [4-7]. A detailed review of the clinical manifestation is beyond the scope of this paper, and the readers are referred to recent excellent reviews $[8,9]$.

\section{Current Methods for Diagnosis and Amyloid Typing}

Suspected amyloidosis is confirmed by positive Congo Red staining, with red-green dichroism/birefringence under polarized light microscopy [10]. Typing is currently achieved by a multidisciplinary diagnostic approach and requires detailed clinical evaluation combined with immunohistochemical (IHC) studies [11], biochemical tests [12], genetic 
TABLE 1: Common types of amyloidosis and treatment options [9, 64].

\begin{tabular}{llclll}
\hline $\begin{array}{l}\text { Amyloid } \\
\text { protein }\end{array}$ & Precursor & $\begin{array}{c}\text { Systemic (S) or } \\
\text { localized (L) }\end{array}$ & Organ involvement & Aetiology & Treatment options \\
\hline AL & $\begin{array}{l}\text { Immunoglobulin kappa } \\
\text { or lambda light chain }\end{array}$ & $\mathrm{S}, \mathrm{L}$ & $\begin{array}{l}\text { Cardiac, renal, hepatic, } \\
\text { PNS, and soft tissues }\end{array}$ & $\begin{array}{l}\text { Primary or myeloma } \\
\text { associated }\end{array}$ & $\begin{array}{l}\text { Chemotherapy, stem } \\
\text { cell transplant }\end{array}$ \\
ATTR & Transthyretin & $\mathrm{S}$ & Cardiac, PNS, GIT, CTS & Hereditary & Liver transplant \\
ATTR & Transthyretin & $\mathrm{S}$ & Cardiac, CTS & Senile & Supportive care \\
AA & (Apo)serum amyloid A & $\mathrm{S}$ & Renal & Secondary to chronic \\
inflammation
\end{tabular}

${ }^{1}$ Recommended amyloid protein nomenclature includes prefix A [3]. PNS: peripheral nervous system; GIT: gastrointestinal tract; CTS: carpal tunnel syndrome.

studies [1], and sometimes functional imaging [13]. When applied to amyloid deposits, IHC on formalin-fixed paraffinembedded (FFPE) tissues often suffers from low specificity and sensitivity $[11,14]$. There are several reasons for this. Firstly, antibodies produced against native precursor proteins are often ineffective in detecting aberrantly produced and misfolded amyloid counterparts. Genetic mutations can also cause loss of epitope in the amyloid protein. This problem is exemplified by the over 80 amyloid-causing mutations in transthyretin. Furthermore, one of the most common amyloid precursor proteins is immunoglobulin light chain. Due to the hypervariable nature of immunoglobulins, antibodies are generally produced against the constant regions, meaning these antibodies are unresponsive against truncated AL proteins expressing variable regions. Finally, the formalin fixation process also traps the abundant normal serum protein counterparts in the tissue sections, a process called "contamination", causing high nonspecific background staining [15].

Since amyloidosis is usually related to an underlying disorder or genetic mutation, diagnosis of the primary disease may help determine the type of amyloid present. Clinically however, genetic and pathological predisposition does not always equate to type of amyloidosis and, there is significant overlap between the disease phenotypes of the various amyloid subtypes. For example, discovery of a clonal plasma cell population, which is usually associated with AL amyloidosis, may actually be an incidental finding as monoclonal gammopathy of undetermined significance is not uncommon in the elderly [1]. Similarly, while the presence of a family history is important to diagnose hereditary amyloidosis, a low penetrance in carriers of the mutation, overlapping involvement of organs usually affected in acquired (AL and AA) amyloidosis, and failure of IHC typing to identify the mutant protein can result in misdiagnosis of hereditary as an acquired amyloidosis [16]. In addition, various atypical cases have been reported in the literature, and copopulations of amyloid proteins have been found in amyloid deposits. Furthermore, different amyloid subtypes can deposit in different organs in an individual further complicating amyloid typing and subsequent management [17-21]. These factors illustrate the difficulty in subtyping amyloidosis which is very important because correct diagnosis is the key to effective treatment.

\section{Current Proteomics Technology}

Before introduction of protein identification by mass spectrometry, N-terminal Edman degradation was the method of choice for protein sequencing [22]. This method involves the sequential addition of a phenylisothiocyanate (PITC) probe to and cleavage of the N-terminal amino acid. The released phenylthiohydantoin (PTH) amino acid is identified by HPLC analysis. The process can be repeated to analyse subsequent amino acids, with a limit of approximately 30 .

Proteomics studies differ from protein biochemistry studies with the aim of detecting and measuring the entire complement of the proteome. This goal required highthroughput protein identification methods. Advent of modern proteomics technology was shaped by the completion of the Human Genome Project and development of other genome databases, together with advances in high-resolution mass spectrometry. Before considering recent research and future prospects in using mass spectrometry to identify amyloid proteins, it is pertinent to review mass spectrometrybased protein identification techniques and how they relate to amyloidosis typing.

Two aspects need to be considered in mass spectrometryassisted amyloidosis typing: (a) sample source selection and preparation and (b) mass spectrometry and bioinformatics analysis.

3.1. Sample Source Selection and Preparation. The amyloidcausing protein must be isolated from normal tissue proteins to enable its identification. Since amyloidosis can also result from overproduction of wild-type proteins, direct analysis of the amyloid deposit is necessary to ensure identification of the causal protein. Analysis of Congo Red-positive regions of FFPE samples is the most straightforward method. However, protein recovery from FFPE samples presents several challenges: the paraffin wax must be removed, and the fixation reversed before the proteins can be extracted with any efficiency. Since archival FFPE blocks are a rich source of clinical samples, several protocols have been developed to overcome these issues $[23,24]$.

Other sources have been suggested including abdominal adipose tissue [25-27] and serum [13, 28-30]. In particular, the possibility of a noninvasive serum-based amyloidosis diagnostic test is very attractive. The difficulty in using 
serum or normal tissue as a sample is the technical challenge of separating amyloid protein from normal tissue protein without the guidance of Congo Red staining. Apart from immuno-isolation using antibody to the suspected amyloid protein, currently there is no structural-based method to separate amyloid fibrils from normal serum or tissue proteins.

Mass spectrometry is a concentration-dependent technique, where the higher abundance analytes will be preferentially analysed. Hence, apart from samples containing few proteins, such as amyloid deposit extract, one or more separation steps need to be performed to ensure depth of coverage. Proteins can be separated by one- or two-dimensional gels or by liquid chromatography (LC). One-dimensional sodium dodecyl sulphate polyacrylamide gel electrophoresis (SDS-PAGE) separates proteins by size and is a simple and robust method for protein separation. Two-dimensional gel electrophoresis (2DE) allows higher resolution of a complex protein mixture. Proteins are first separated on the basis of their charge by isoelectric point focussing (IEF), and then by size using SDS-PAGE. Analytes are separated according to physical properties such as charge or hydrophobicity. Reverse phase LC has been used to separate amyloid proteins from other tissue proteins by preferential elution at $35-45 \%$ acetonitrile [11]. Peptide level separation is generally performed by reverse phase LC using C18 columns online with an electrospray mass spectrometer.

3.2. Mass Spectrometry and Bioinformatics. Several mass spectrometry methods are now routinely used for protein identification with standard mass spectrometers readily available in research facilities. Mass spectrometry measures the mass of charged (ionized) analyte (protein or peptide), recorded as a mass-to-charge ratio $(\mathrm{m} / \mathrm{z})$. Mass spectrometers are classified according to their mode of ionization and the type of mass analyser. There are two main modes of ionization, MALDI (matrix-assisted laser desorption ionization) and ESI (electrospray ionization). Mass analysers can be divided into two main types, TOF (time-of-flight) and Q (quadrupole), with ion trap being a subtype of quadrupole analysers which traps selected ions hence allowing greater sensitivity. The discussion here will be restricted to mass spectrometers commonly used in nonspecialist laboratories as these instruments will be most accessible for clinical diagnostics.

Mass spectrometric identification of proteins is based on the concept that all naturally occurring mammalian amino acids (except for the leucine and isoleucine pair) have a unique mass, and hence each combination of sequences will correlate with a specific mass. Proteins may be analysed intact ("top-down" proteomics) to obtain the mass of the entire protein. However, since many proteins will have the same total mass, and due to the current limits in the range of $\mathrm{m} / \mathrm{z}$ detection, "bottom-up" proteomics is more commonly used for protein identification. In "bottom-up" proteomics, proteins are proteolytically cleaved into peptides prior to mass spectrometry, and protein identities are inferred from the identified peptides.
In highly purified samples (containing $1-5$ proteins), sufficient information is gained from the masses of the proteolytic peptides to identify the protein(s), a method called peptide mass fingerprinting (PMF) [31-34]. In a typical PMF experiment, gel-separated proteins are excised and subjected to in-gel digest with trypsin, which cleaves C-terminal of arginine and lysine (except before proline). The $\mathrm{m} / \mathrm{z}$ ratios of tryptic peptides are then measured to generate a peptide fingerprint of the protein(s) which were then matched against in-silico tryptic digest of the entire database using specifically designed algorithms. MALDI-TOF is usually the mass spectrometer used for PMF analysis due to speed and ease of use. While PMF does not actually provide sequence information, by further fragmenting selected peptide ions and detecting the resulting daughter ions in a second mass analyser, sequence information can be obtained by a similar spectral matching algorithm. This method is called tandem mass spectrometry (MS/MS or tandem MS) [35] and is commonly used with electrospray mass spectrometers, although MALDI-TOF/TOF instruments are also now widely used.

Protein identification both PMF and MS/MS requires database searching using specialist software and sequence databases. Since the principle of these methods rely on matching the experimental spectra to theoretical spectra generated from a sequence database, it follows that only sequences within the selected database has a chance of being "identified". De novo MS/MS peptide sequencing without the reference to a sequence database can be performed manually by correlating the mass difference between MS/MS peaks [36]. Understandably, manual interpretation has not gained popularity with researchers undertaking proteome-wide studies. Many algorithms have been developed for automated de novo sequencing over the past decade [37-43].

The formalin fixation process introduces many chemical alterations to the proteins, which reduces the efficiency of protease cleavage and/or alters the mass of the resulting peptides. These variables must be considered in the bioinformatics analysis to ensure accurate protein identification.

\section{Proteomic Investigations in Amyloidosis Typing}

Given the importance of identifying the culprit protein in amyloidosis, recent years have seen collaborative efforts between clinicians and proteomics researchers in the application of high-resolution mass spectrometry to amyloid identification (Table 2).

One stream of studies focused on the serum as a sample, initially using immune-affinity purification to isolate known amyloid protein followed by mass spectrometers analysis, with the aim of identifying the mutation [28, 29, 44-47]. The methods developed were translated to clinical assays $[28,45]$, however, these methods require antibody of high specificity, and some mutations may destroy the antigenic epitope leading to reduction or loss of antibody binding. In addition, amyloid proteins may preferentially deposit in tissue leading to low serum levels. Furthermore, genetic mutation is already routinely identified through DNA sequencing 


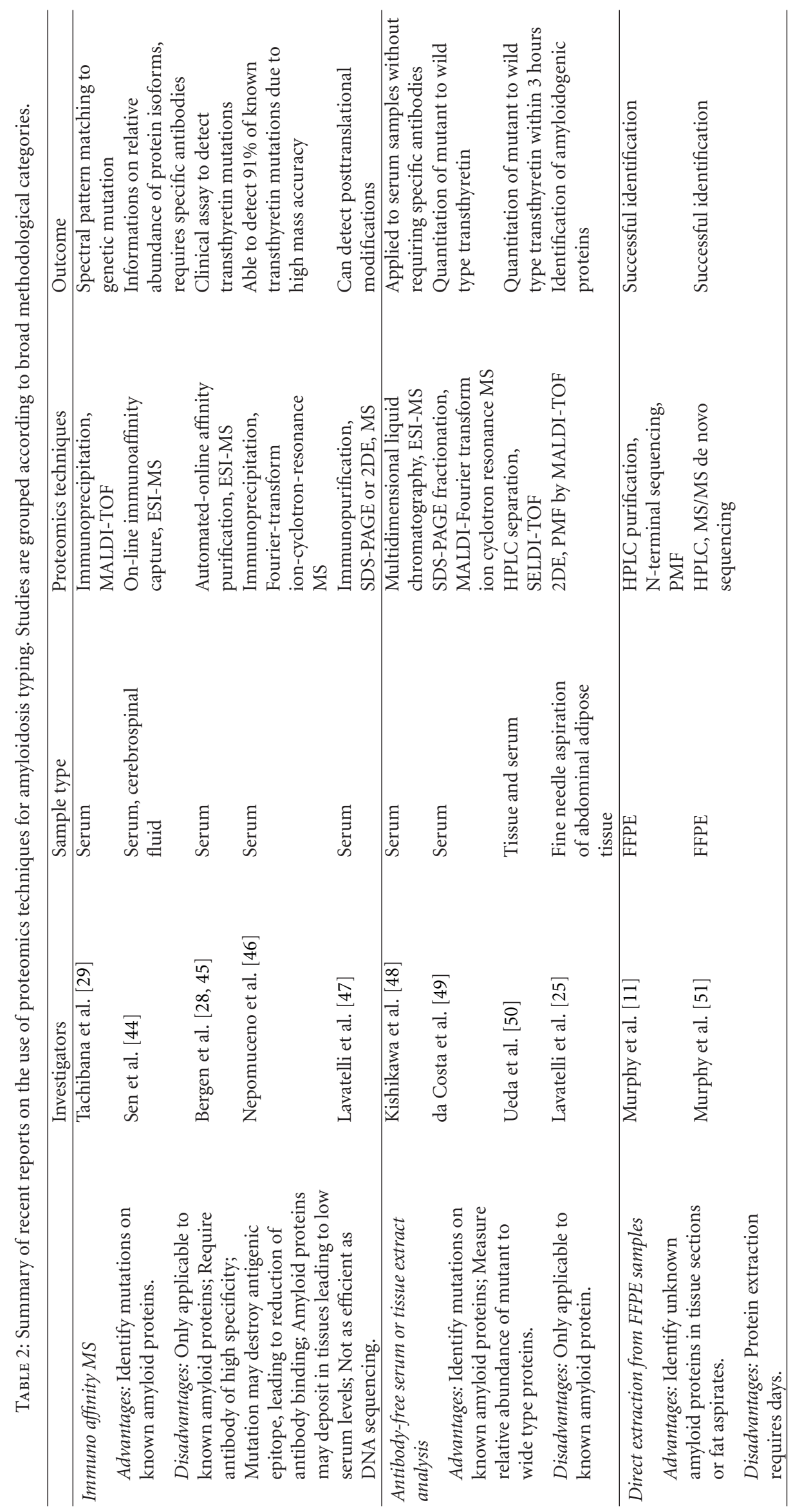




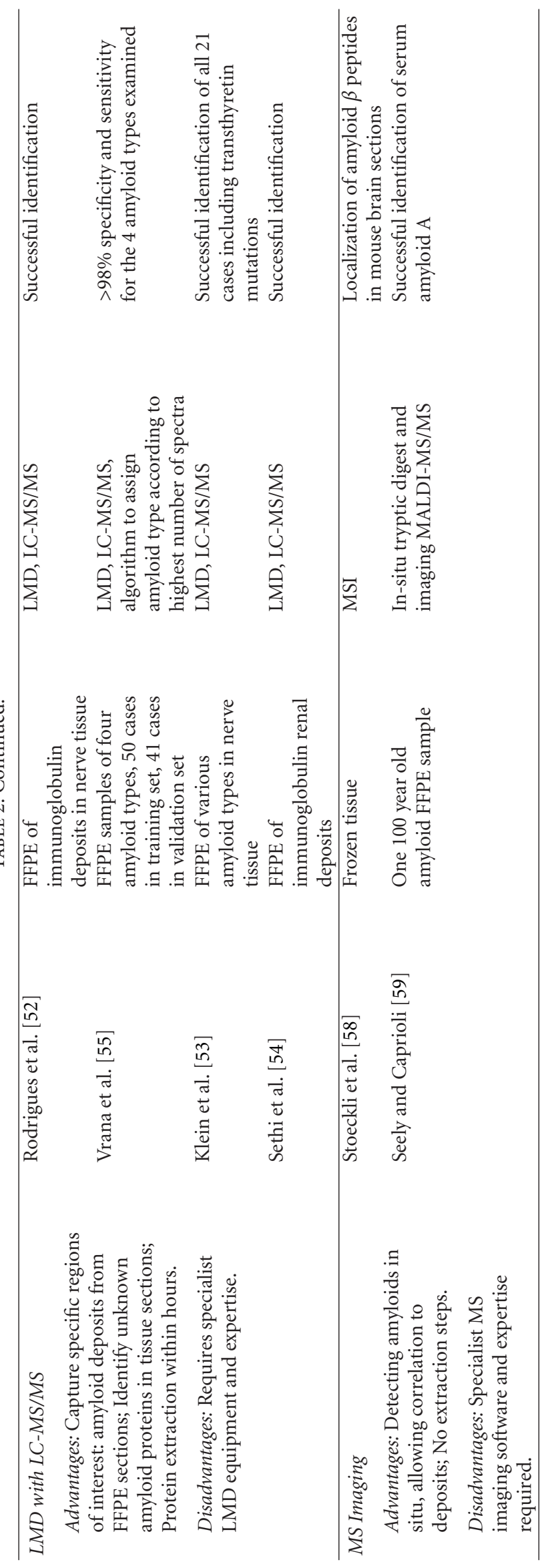


with high accuracy. Recognising the pitfalls of antibodybased methods, alternative, nonimmune strategies were devised for tissue and/or serum analysis. These include use of multidimensional HPLC separation [48], SDS-PAGE fractionation then excising region according to predicted size of the (known) amyloid protein [49] and HPLC separation following by binding to an activated MALDI surface, a method termed Surface-Enhanced Laser Desorption Ionisation (SELDI) [50]. Most of these methods were designed to detect mutation in known amyloid protein (usually transthyretin) and to measure the relative abundance of mutant to wild-type proteins.

In order to identify unknown amyloid proteins, an antibody-free method based on analysis of the actual amyloid deposit is required. Tissue biopsies are routinely processed into FFPE samples. FFPE-processed samples have not been extensively used in proteomics studies due to the potential chemical alterations and difficulty in protein extraction. In an early study, Murphy et al. [11] extracted protein samples from multiple FFPE slides of different amyloid types. Extraction was performed by denaturing the scraped slides in a solution containing $50 \mathrm{mM}$ Tris- $\mathrm{HCl}, \mathrm{pH} 8.0,0.2 \mathrm{M}$ EDTA, and $6.4 \mathrm{M}$ guanidine hydrochloride at $37^{\circ} \mathrm{C}$ for up to 5 days, and sonicating until the solution is clear. Amyloid proteins were purified by HPLC and identified by Edman sequencing. Samples that could not be sequenced were analysed by peptide mass fingerprinting. In a follow-up study, the authors used a similar method, with the incubation time increased to 8-10 days with daily sonication, to extract amyloid proteins from FFPE slides and abdominal fat aspirates and adopted de novo sequencing by tandem mass spectrometry [51]. Although too time consuming as clinical pathology procedures, these studies demonstrate the potential for proteomic identification of amyloids from FFPE samples.

Instead of the extensive purification steps, a team from the Mayo Clinic pioneered the use of laser microdissection (LMD) to capture amyloid deposits from FFPE sections, followed by ESI-MS identification [52-55]. LMD utilizes cleverly designed caps with computer-guided laser to capture regions of interest from tissue sections [56]. Extraction used a mild solution containing $10 \mathrm{mM}$ Tris, $1 \mathrm{mM}$ EDTA, $0.0002 \%$ Zwittergent3-16 and was shortened to 90 minutes at $98^{\circ} \mathrm{C}$, followed by 60 minutes of sonication. Following tryptic digest, peptides of were analysed with LC-tandem mass spectrometry. Using a training set of 4 amyloid subtypes to design an algorithm, Vrana et al. reported greater than $98 \%$ specificity and sensitivity for their assay in detecting the amyloid subtypes used in training the algorithm [55]. We have successfully extracted proteins from LMD-dissected amyloid deposits using a commercial FFPE Protein Extraction Solution (Agilent) with a 10 minute incubation at $95^{\circ} \mathrm{C}$, followed by 2 hours at $60^{\circ} \mathrm{C}$.

A novel method correlating MS data with tissue location is mass spectrometry imaging (MSI). Like traditional immunohistochemistry for amyloid detection, tissue sections are mounted on activated glass slides but are processed by a robotic liquid handler to dispense protease and then matrix, and analysed using MALDI-TOF with MS imaging software [57]. This method has the advantage of detecting amyloids in situ, allowing correlation to the deposit. A proofof-concept study used fresh frozen mouse brain tissue to correlated amyloid $\beta$ peptide with immunostaining of consecutive sections [58]. In a follow-up report, MSI analysis successfully identified the amyloid type in a FFPE amyloid sample that has been preserved for over 100 years [59].

\section{Outlook for Proteomics in Amyloidosis Typing}

Although relative few in number, recent studies have aptly demonstrated feasibility in mass-spectrometry-based amyloid typing. Indeed, LMD-MS is currently the gold standard for amyloid subtyping [4]. A clinically useful assay needs to be accurate, fast, and suitable for the relevant sample type. Although highly accurate, LMD is not a fast technique, requiring 1-1.5 hour per slide even in experienced hands [56]. After LMD, sample preparation requires a further 1-2 days to undergo fixation reversal, protein denaturation, and proteolytic digestion.

One possibility is to combine the LMD and MS steps by using imaging MALDI-MS/MS (MSI-MS/MS). Recent pilot studies point to the potential for using MSI-MS/MS for amyloid-type identification from FFPE sections [59]. The lack of protein/peptide separation steps in MSI-MS/MS limits the depth of proteome coverage able to be achieved in this technique. However, this limitation is not a problem for amyloid deposits which contains 1 or 2 major proteins, which are the amyloid proteins of interest. Hence the possibility of directly using Congo Red-stained FFPE section for guided MSI-MS/MS in amyloid typing is an exciting prospect. Furthermore, this technique is more likely to achieve wide practical use in clinic as it is much more streamlined and requires less sample handling compared to LMD-MS. The time-Furthermore steps in LMD-MS include LMD, the extensive extraction steps and tryptic cleavage. MSI-MS/MS does not require LMD or protein extraction, and the tryptic cleavage is faster because it occurs in much smaller volumes (on droplets sprayed on the slide). MSI-MS/MS can also be adapted for the analysis of tissue microarray and fresh frozen tissue samples of different clinical conditions in histopathology. Results from MSI-MS/MS can be correlated with adjacent tissue sections analyse by immunohistochemistry to coordinate protein identity and location. With the possibility to automate samples preparation, MSI-MS/MS is an attractive technique for the clinical pathology laboratory.

Another important area of development is bioinformatic analysis software for de novo peptide sequencing [37-40, 42, $60,61]$, and those combining de novo peptide sequencing (sequence tag) with MS/MS database searching for protein identification [41, 62]. Performance of de novo sequencing is likely crucial to successful amyloidosis typing due to (1) high likelihood of mutations and immunoglobulin variable regions that are not in the sequence database, and (2) increased likelihood of chemical modifications due to FFPE processing. Hence deployment of an accurate de novo sequencing algorithm with or without MS/MS database 
matching should be considered in proteomics analysis of amyloid deposits.

In conclusion, technical advances in mass spectrometry and development of bioinformatic algorithms have matured to bring mass-spectrometry-based amyloidosis typing diagnostics. Mass spectrometry techniques are already being used in clinical pathology [63]. The tissue slide sample format of MSI-MS/MS is a comparable and complementary technique to immunohistochemistry. With automated samples preparation and development of diagnostic algorithms, MSIMS/MS will be extremely useful for clinical amyloidosis subtyping in the near future.

\section{Acknowledgment}

M. M. Hill is supported by a National Health and Medical Research Council of Australia Career Development Fellowship.

\section{References}

[1] H. J. Lachmann, D. R. Booth, S. E. Booth et al., "Misdiagnosis of hereditary amyloidosis as AL (primary) amyloidosis," The New England Journal of Medicine, vol. 346, no. 23, pp. 17861791, 2002.

[2] S. S. Bhupathi, S. Chalasani, and R. Rokey, "Stiff heart syndrome," Clinical Medicine \& Research, vol. 9, no. 2, pp. 92-99, 2011.

[3] J. D. Sipe, M. D. Benson, J. N. Buxbaum et al., "Amyloid fibril protein nomenclature: 2010 recommendations from the nomenclature committee of the International Society of Amyloidosis," Amyloid, vol. 17, no. 3-4, pp. 101-104, 2010.

[4] A. D. Cohen and R. L. Comenzo, "Systemic light-chain amyloidosis: advances in diagnosis, prognosis, and therapy," $\mathrm{He}$ matology, vol. 2010, pp. 287-294, 2010.

[5] M. A. Gertz, "Immunoglobulin light chain amyloidosis: 2011 update on diagnosis, risk-stratification, and management," American Journal of Hematology, vol. 86, no. 2, pp. 180-186, 2011.

[6] Y. Sekijima et al., Familial Transthyretin Amyloidosis, 1993.

[7] R. L. Comenzo, "Managing systemic light-chain amyloidosis," JNCCN: Journal of the National Comprehensive Cancer Network, vol. 5, no. 2, pp. 179-187, 2007.

[8] R. L. Comenzo, "How I treat amyloidosis," Blood, vol. 114, no. 15, pp. 3147-3157, 2009.

[9] K. Sideras and M. A. Gertz, "Amyloidosis.," Advances in clinical chemistry, vol. 47, pp. 1-44, 2009.

[10] M. M. Picken, "Amyloidosis-where are we now and where are we heading?" Archives of Pathology and Laboratory Medicine, vol. 134, no. 4, pp. 545-551, 2010.

[11] C. L. Murphy, M. Eulitz, R. Hrncic et al., "Chemical typing of amyloid protein contained in formalin-fixed paraffin-embedded biopsy specimens," American Journal of Clinical Pathology, vol. 116, no. 1, pp. 135-142, 2001.

[12] R. A. Kyle and M. A. Gertz, "Primary systemic amyloidosis: clinical and laboratory features in 474 cases," Seminars in Hematology, vol. 32, no. 1, pp. 45-59, 1995.

[13] P. N. Hawkins, "Serum amyloid P component scintigraphy for diagnosis and monitoring amyloidosis," Current Opinion in Nephrology and Hypertension, vol. 11, no. 6, pp. 649-655, 2002.
[14] A. A. Satoskar, K. Burdge, D. J. Cowden, G. M. Nadasdy, L. A. Hebert, and T. Nadasdy, "Typing of amyloidosis in renal biopsies: diagnostic pitfalls," Archives of Pathology and Laboratory Medicine, vol. 131, no. 6, pp. 917-922, 2007.

[15] A. Solomon, C. L. Murphy, and P. Westermark, "Unreliability of immunohistochemistry for typing amyloid deposits," Archives of Pathology and Laboratory Medicine, vol. 132, no. 1, p. 14, 2008.

[16] M. J. Saraiva, "Hereditary transthyretin amyloidosis: molecular basis and therapeutical strategies," Expert Reviews in Molecular Medicine, vol. 4, no. 12, pp. 1-11, 2002.

[17] J. Bergström, C. L. Murphy, D. T. Weiss et al., "Two different types of amyloid deposits-apolipoprotein A-IV and transthyretin-in a patient with systematic amyloidosis," Laboratory Investigation, vol. 84, no. 8, pp. 981-988, 2004.

[18] L. H. Connors, T. Prokaeva, A. Lim et al., "Cardiac amyloidosis in African Americans: comparison of clinical and laboratory features of transthyretin V122I amyloidosis and immunoglobulin light chain amyloidosis," American Heart Journal, vol. 158, no. 4, pp. 607-614, 2009.

[19] E. Menet, M. L. Petit, F. Bridoux et al., "Bilateral combined $\beta 2$ microglobulin and AL amyloidomas of the buttocks in a long term hemodialysis patient," Nephrologie, vol. 22, no. 3, pp. 115-118, 2001.

[20] A. J. Cowan et al., "Macroglossia—not always AL amyloidosis," Amyloid, vol. 18, no. 2, pp. 83-86, 2011.

[21] R. L. Comenzo, P. Zhou, M. Fleisher, B. Clark, and J. TeruyaFeldstein, "Seeking confidence in the diagnosis of systemic AL (Ig light-chain) amyloidosis: patients can have both monoclonal gammopathies and hereditary amyloid proteins," Blood, vol. 107, no. 9, pp. 3489-3491, 2006.

[22] K. D. Speicher, N. Gorman, and D. W. Speicher, "N-terminal sequence analysis of proteins and peptides," Current Protocols in Protein Science, chapter 11, unit11 10, 2009.

[23] O. Azimzadeh, Z. Barjaktarovic, M. Aubele et al., "Formalinfixed paraffin-embedded (FFPE) proteome analysis using gelfree and gel-based proteomics," Journal of Proteome Research, vol. 9, no. 9, pp. 4710-4720, 2010.

[24] M. S. Scicchitano, D. A. Dalmas, R. W. Boyce, H. C. Thomas, and K. S. Frazier, "Protein extraction of formalin-fixed, paraffin-embedded tissue enables robust proteomic profiles by mass spectrometry," Journal of Histochemistry and Cytochemistry, vol. 57, no. 9, pp. 849-860, 2009.

[25] F. Lavatelli, D. H. Perlman, B. Spencer et al., "Amyloidogenic and associated proteins in systemic amyloidosis proteome of adipose tissue," Molecular and Cellular Proteomics, vol. 7, no. 8, pp. 1570-1583, 2008.

[26] P. Westermark, L. Benson, J. Juul, and K. Sletten, "Use of subcutaneous abdominal fat biopsy specimen for detailed typing of amyloid fibril protein-AL by amino acid sequence analysis," Journal of Clinical Pathology, vol. 42, no. 8, pp. 817-819, 1989.

[27] P. Westermark, E. Davey, K. Lindbom, and S. Enqvist, "Subcutaneous fat tissue for diagnosis and studies of systemic amyloidosis," Acta Histochemica, vol. 108, no. 3, pp. 209-213, 2006.

[28] H. R. Bergen III, S. R. Zeldenrust, and S. Naylor, "An on-line assay for clinical detection of amyloidogenic transthyretin variants directly from serum," Amyloid, vol. 10, no. 3, pp. 190197, 2003.

[29] N. Tachibana, T. Tokuda, K. Yoshida et al., "Usefulness of MALDI/TOF mass spectrometry of immunoprecipitated serum variant transthyretin in the diagnosis of familial amyloid polyneuropathy," Amyloid, vol. 6, no. 4, pp. 282-288, 1999. 
[30] R. Théberge, L. Connors, M. Skinner, J. Skare, and C. E. Costello, "Characterization of transthyretin mutants from serum using immunoprecipitation, HPLC/electrospray ionization and matrix-assisted laser desorption/ionization mass spectrometry," Analytical Chemistry, vol. 71, no. 2, pp. 452-459, 1999.

[31] D. J. C. Pappin, P. Hojrup, and A. J. Bleasby, "Rapid identification of proteins by peptide-mass fingerprinting," Current Biology, vol. 3, no. 6, pp. 327-332, 1993.

[32] J. R. Yeats III, S. Speicher, P. R. Griffin, and T. Hunkapiller, "Peptide mass maps: a highly informative approach to protein identification," Analytical Biochemistry, vol. 214, no. 2, pp. 397-408, 1993.

[33] M. Mann, P. Hojrup, and P. Roepstorff, "Use of mass spectrometric molecular weight information to identify proteins in sequence databases," Biological Mass Spectrometry, vol. 22, no. 6, pp. 338-345, 1993.

[34] W. J. Henzel, T. M. Billeci, J. T. Stults, S. C. Wong, C. Grimley, and C. Watanabe, "Identifying proteins from two-dimensional gels by molecular mass searching of peptide fragments in protein sequence databases," Proceedings of the National Academy of Sciences of the United States of America, vol. 90, no. 11, pp. 5011-5015, 1993.

[35] D. F. Hunt, J. R. Yates, and J. Shabanowitz, "Protein sequencing by tandem mass spectrometry," Proceedings of the National Academy of Sciences of the United States of America, vol. 83, no. 17, pp. 6233-6237, 1986.

[36] T. Addona and K. Clauser, "De novo peptide sequencing via manual interpretation of MS/MS spectra," Current Protocols in Protein Science, chapter 16, unit 16 11, 2002.

[37] L. Mo, D. Dutta, Y. Wan, and T. Chen, "MSNovo: a dynamic programming algorithm for de novo peptide sequencing via tandem mass spectrometry," Analytical Chemistry, vol. 79, no. 13, pp. 4870-4878, 2007.

[38] M. Kanazawa, H. Anyoji, A. Ogiwara, and U. Nagashima, "De novo peptide sequencing using ion peak intensity and amino acid cleavage intensity ratio," Bioinformatics, vol. 23, no. 9, pp. 1068-1072, 2007.

[39] A. M. Frank, M. M. Savitski, M. L. Nielsen, R. A. Zubarev, and P. A. Pevzner, "De novo peptide sequencing and identification with precision mass spectrometry," Journal of Proteome Research, vol. 6, no. 1, pp. 114-123, 2007.

[40] M. T. Olson, J. A. Epstein, and A. L. Yergey, "De novo peptide sequencing using exhaustive enumeration of peptide composition," Journal of the American Society for Mass Spectrometry, vol. 17, no. 8, pp. 1041-1049, 2006.

[41] B. D. Halligan, V. Ruotti, S. N. Twigger, and A. S. Greene, "DeNovoID: a web-based tool for identifying peptides from sequence and mass tags deduced from de novo peptide sequencing by mass spectroscopy," Nucleic Acids Research, vol. 33, no. 2, pp. W376-W381, 2005.

[42] R. Bruni, G. Gianfranceschi, and G. Koch, "On peptide de novo sequencing: a new approach," Journal of Peptide Science, vol. 11, no. 4, pp. 225-234, 2005.

[43] V. Dancik, T. A. Addona, K. R. Clauser, J. E. Vath, and P. A. Pevzner, "De novo peptide sequencing via tandem mass spectrometry," Journal of Computational Biology, vol. 6, no. 3-4, pp. 327-342, 1999.

[44] J. W. Sen, H. R. Bergen III, and N. H. H. Heegaard, "On-line immunoaffinity-liquid chromatography-mass spectrometry for identification of amyloid disease markers in biological fluids," Analytical Chemistry, vol. 75, no. 5, pp. 1196-1202, 2003.
[45] H. R. Bergen, R. S. Abraham, K. L. Johnson, A. R. Bradwell, and S. Naylor, "Characterization of amyloidogenic immunoglobulin light chains directly from serum by on-line immunoaffinity isolation," Biomedical Chromatography, vol. 18, no. 3, pp. 191-201, 2004.

[46] A. I. Nepomuceno, C. J. Mason, D. C. Muddiman, H. R. Bergen, and S. R. Zeldenrust, "Detection of genetic variants of transthyretin by liquid chromatography-dual electrospray ionization Fourier-transform ion-cyclotron-resonance mass spectrometry," Clinical Chemistry, vol. 50, no. 9, pp. 1535-1543, 2004.

[47] F. Lavatelli, F. Brambilla, V. Valentini et al., "A novel approach for the purification and proteomic analysis of pathogenic immunoglobulin free light chains from serum," Biochimica et Biophysica Acta, vol. 1814, no. 3, pp. 409-419, 2011.

[48] M. Kishikawa, T. Nakanishi, A. Miyazaki, and A. Shimizu, "A simple and reliable method of detecting variant transthyretins by multidimensional liquid chromatography coupled to electrospray ionization mass spectrometry," Amyloid, vol. 6, no. 1, pp. 48-53, 1999.

[49] G. da Costa, R. Gomes, C. F. Correia et al., "Identification and quantitative analysis of human transthyretin variants in human serum by Fourier transform ion-cyclotron resonance mass spectrometry," Amyloid, vol. 16, no. 4, pp. 201-207, 2009.

[50] M. Ueda, Y. Misumi, M. Mizuguchi et al., "SELDI-TOF mass spectrometry evaluation of variant transthyretins for diagnosis and pathogenesis of familial amyloidotic polyneuropathy," Clinical Chemistry, vol. 55, no. 6, pp. 1223-1227, 2009.

[51] C. L. Murphy, S. Wang, T. Williams, D. T. Weiss, and A. Solomon, "Characterization of systemic amyloid deposits by mass spectrometry," Methods in Enzymology, vol. 412, pp. 48-62, 2006.

[52] F. J. Rodriguez, J. D. Gamez, J. A. Vrana et al., "Immunoglobulin derived depositions in the nervous system: novel mass spectrometry application for protein characterization in formalin-fixed tissues," Laboratory Investigation, vol. 88, no. 10, pp. 1024-1037, 2008.

[53] C. J. Klein, J. A. Vrana, J. D. Theis et al., "Mass spectrometricbased proteomic analysis of amyloid neuropathy type in nerve tissue," Archives of Neurology, vol. 68, no. 2, pp. 195-199, 2011.

[54] S. Sethi, J. D. Theis, N. Leung et al., "Mass spectrometry-based proteomic diagnosis of renal immunoglobulin heavy chain amyloidosis," Clinical Journal of the American Society of Nephrology, vol. 5, no. 12, pp. 2180-2187, 2010.

[55] J. A. Vrana, J. D. Gamez, B. J. Madden, J. D. Theis, H. R. Bergen, and A. Dogan, "Classification of amyloidosis by laser microdissection and mass spectrometry-based proteomic analysis in clinical biopsy specimens," Blood, vol. 114, no. 24, pp. 4957-4959, 2009.

[56] V. Espina, J. D. Wulfkuhle, V. S. Calvert et al., "Laser-capture microdissection," Nature Protocols, vol. 1, no. 2, pp. 586-603, 2006.

[57] M. Stoeckli, P. Chaurand, D. E. Hallahan, and R. M. Caprioli, "Imaging mass spectrometry: a new technology for the analysis of protein expression in mammalian tissues," Nature Medicine, vol. 7, no. 4, pp. 493-496, 2001.

[58] M. Stoeckli, D. Staab, M. Staufenbiel, K. H. Wiederhold, and L. Signor, "Molecular imaging of amyloid $\beta$ peptides in mouse brain sections using mass spectrometry," Analytical Biochemistry, vol. 311, no. 1, pp. 33-39, 2002.

[59] E. H. Seeley and R. M. Caprioli, "Molecular imaging of proteins in tissues by mass spectrometry," Proceedings of the $\mathrm{Na}$ tional Academy of Sciences of the United States of America, vol. 105, no. 47, pp. 18126-18131, 2008. 
[60] H. Chi, R. X. Sun, B. Yang et al., "PNovo: de novo peptide sequencing and identification using HCD spectra," Journal of Proteome Research, vol. 9, no. 5, pp. 2713-2724, 2010.

[61] L. He and B. Ma, "Adepts: advanced peptide de novo sequencing with a pair of tandem mass spectra," Journal of Bioinformatics and Computational Biology, vol. 8, no. 6, pp. 981-994, 2010.

[62] S. Kim, N. Gupta, N. Bandeira, and P. A. Pevzner, "Spectral dictionaries. Integrating de novo peptide sequencing with database search of tandem mass spectra," Molecular and Cellular Proteomics, vol. 8, no. 1, pp. 53-69, 2009.

[63] M. S. Rashed, "Clinical applications of tandem mass spectrometry: ten years of diagnosis and screening for inherited metabolic diseases," Journal of Chromatography B, vol. 758, no. 1, pp. 27-48, 2001

[64] S. Y. Tan, M. B. Pepys, and P. N. Hawkins, "Treatment of amyloidosis," American Journal of Kidney Diseases, vol. 26, no. 2, pp. 267-285, 1995. 

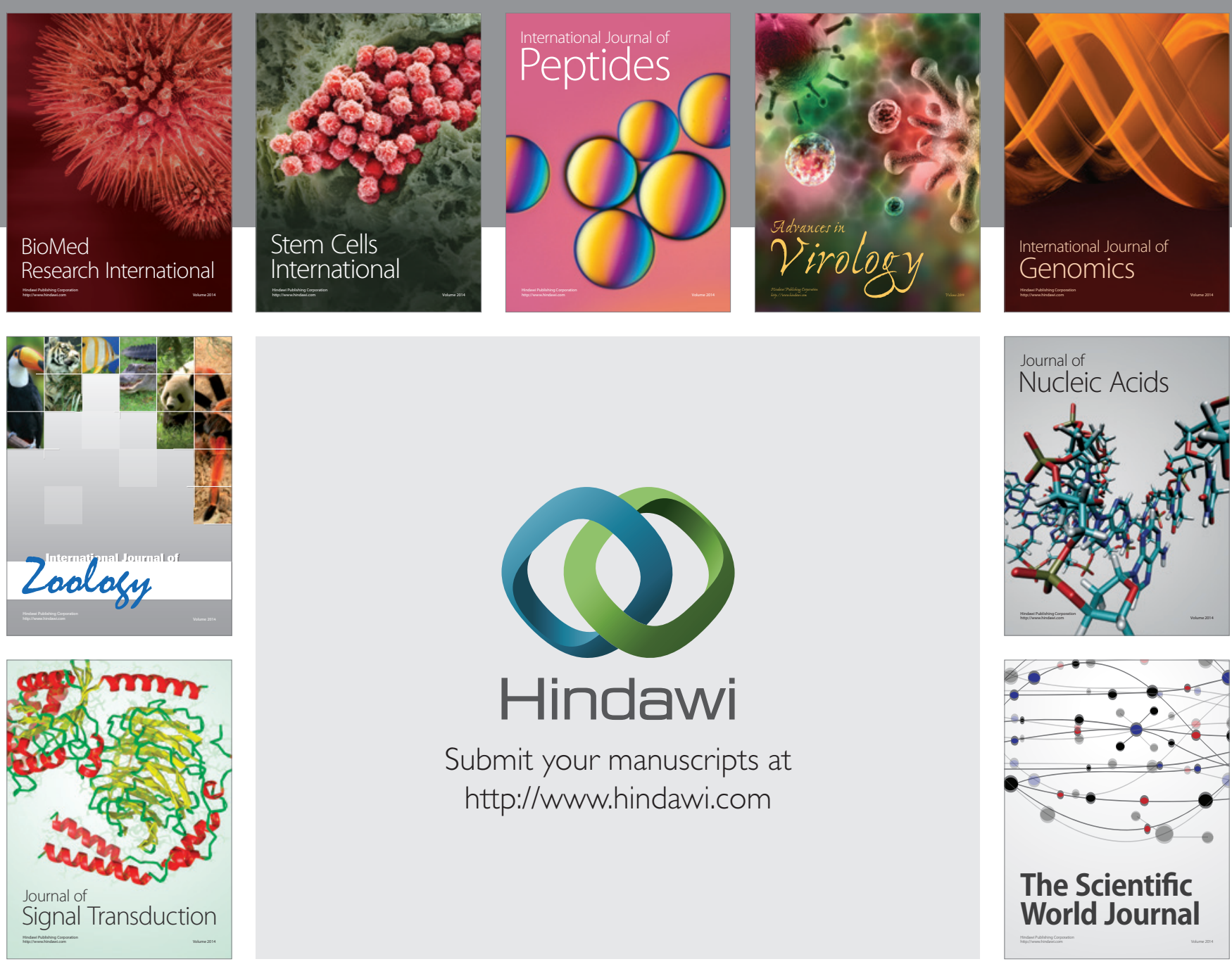

Submit your manuscripts at

http://www.hindawi.com
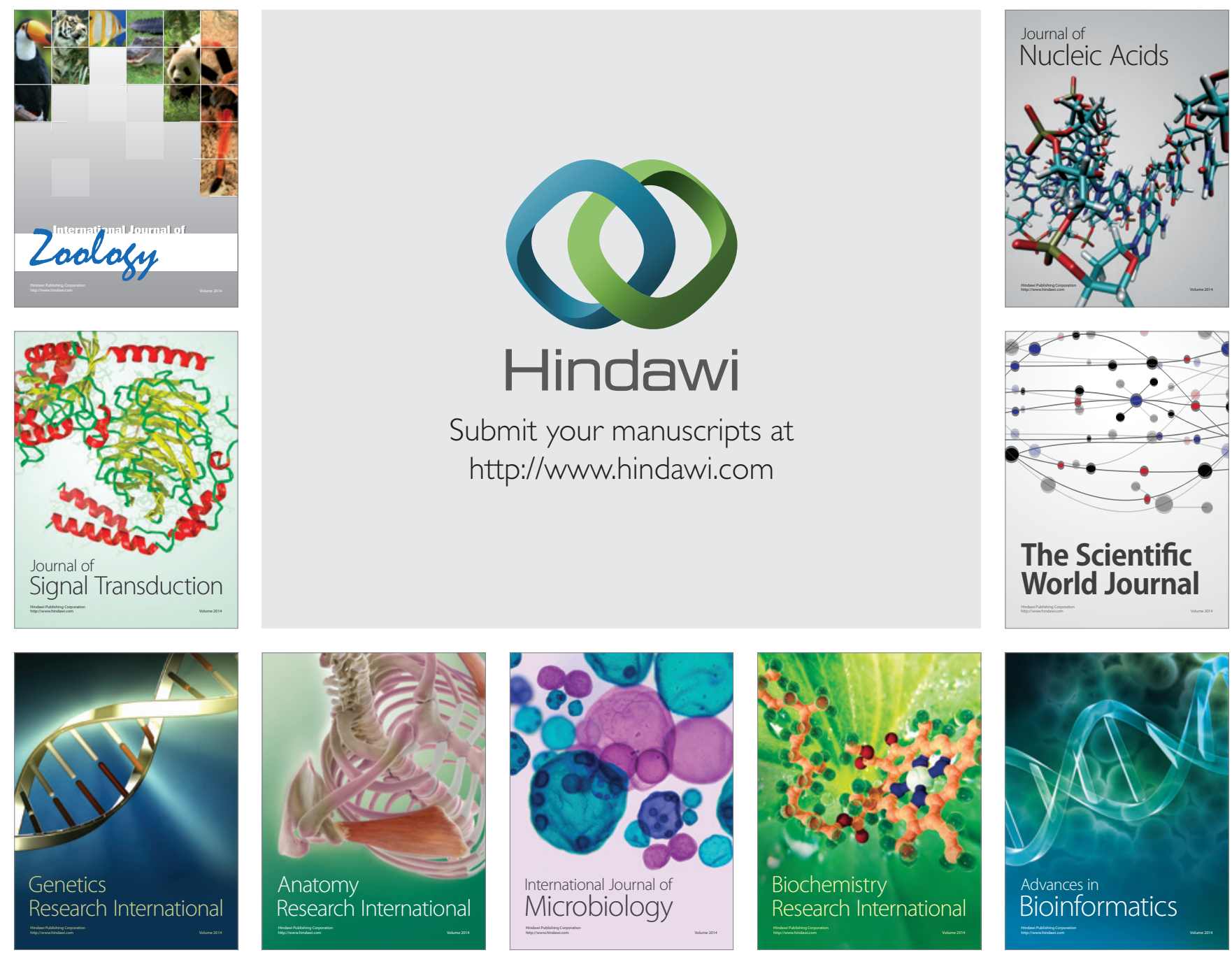

The Scientific World Journal
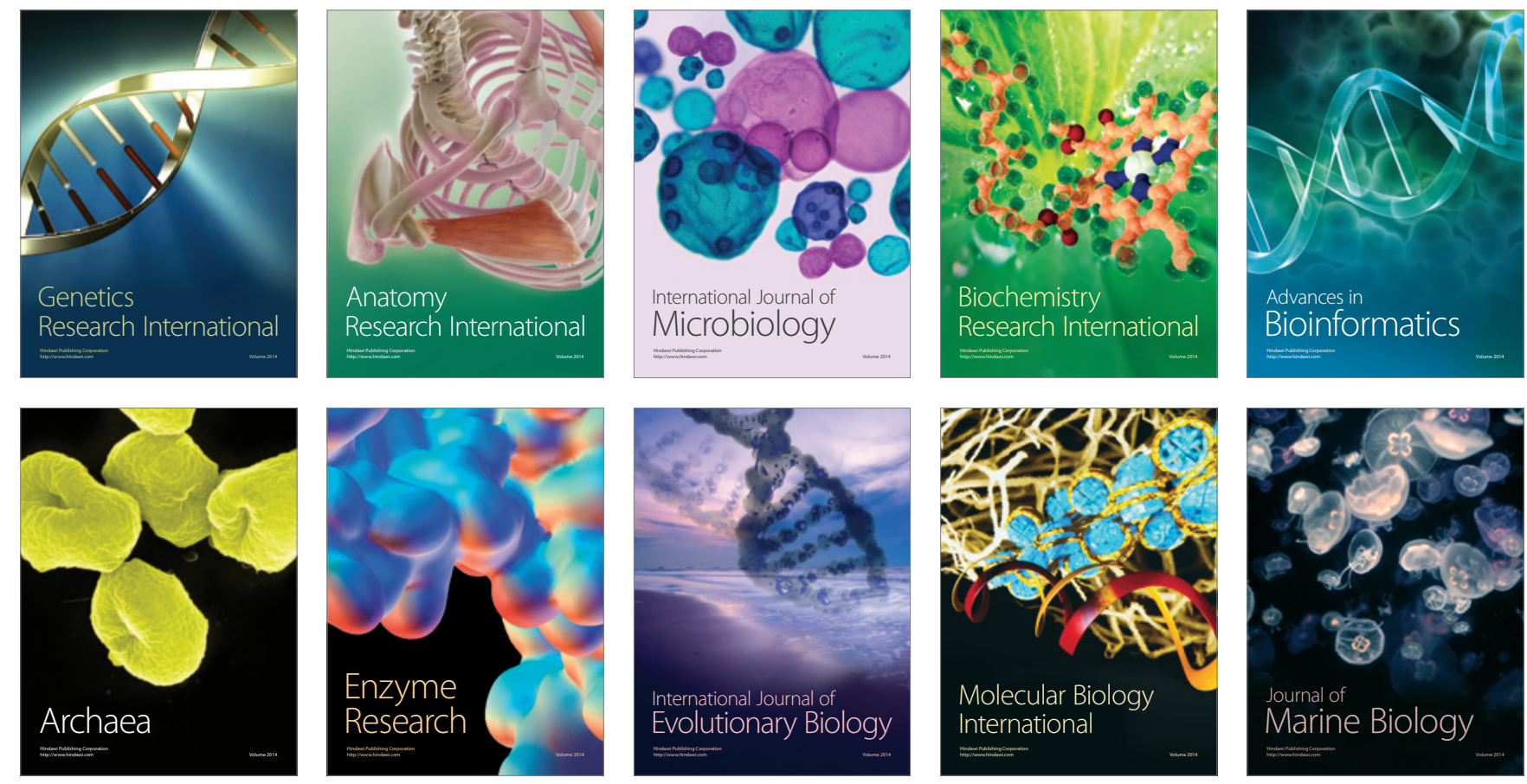